Review Article

\title{
Study on the Impact Resistance of Metal Flexible Net to Rock fall
}

\author{
Gaosheng Wang, ${ }^{1,2}$ Yunhou Sun $\mathbb{D}^{1},{ }^{1}$ Ao Zhang, ${ }^{1}$ Lei Zheng, ${ }^{1}$ Yuzheng Lv, ${ }^{1}$ Huajie Wu, \\ and Yuanyou Yang ${ }^{3}$
}

${ }^{1}$ Institute of Defense Engineering, Academy of Military Sciences, Beijing 100036, China

${ }^{2}$ The Troops 63926 of PLA, Beijing 100192, China

${ }^{3}$ Agency Affairs Bureau of PLA, Beijing 100082, China

Correspondence should be addressed to Yunhou Sun; houyunsun@126.com

Received 24 October 2019; Revised 17 January 2020; Accepted 3 June 2020; Published 27 June 2020

Academic Editor: Marco Gherlone; marco.gherlone@polito.it

Copyright (c) 2020 Gaosheng Wang et al. This is an open access article distributed under the Creative Commons Attribution License, which permits unrestricted use, distribution, and reproduction in any medium, provided the original work is properly cited.

\begin{abstract}
Based on experiments and finite element analysis, the impact resistance of metal flexible net was studied, which can provide reference for the application of metal flexible net in rock fall protection. The oblique (30 degrees) impact experiment of metal flexible net was carried out, the corresponding finite element (FE) to the experiment was established, and the FE model was verified by simulation results to the experimental tests from three aspects: the deformation characteristics of metal flexible net, the time history curves of impact force on supporting ropes, and the maximum instantaneous impact force on supporting ropes. The FE models of metal flexible nets with inclination angles of $0,15,30,45,60$, and 75 degrees were established, and the impact resistance of metal flexible nets with different inclination angles was analyzed. The research shows that the metal flexible net with proper inclination can bounce the impact rock fall out of the safe area and prevent rock fall falling on the metal flexible net, thus realizing the self-cleaning function. When the inclination angle of the metal flexible net is 15,30 , and 45 degrees, respectively, the bounce effect after impact is better, the remaining height is improved, the protection width is improved obviously, and the impact force is reduced. Herein, the impact force of rock fall decreases most obviously at 45 degrees inclination, and the protective performance is relatively good.
\end{abstract}

\section{Introduction}

Flexible protection system is an efficient protection method to protect rock fall which is composed of metal flexible net, steel ropes, and supporting structure (Figure 1). As the main energy-consuming component of the flexible protection system, the metal flexible net is braided by special steel wires with high strength and hard surface [1-6]. The braiding mode of steel wires enables it to achieve the optimal transmission of force through the adaptive adjustment between high strength steel wires under the action of external forces. Therefore, the metal flexible net has been used widely [7, 8]. Del Coz Daz et al. [9] established a FE model of the metal flexible net by employing BEAM 189 element, and the in-plane mechanical properties of the metal flexible net was researched. Nicot et al. $[10,11]$ fixed the metal flexible net on a steel frame, carried out an experimental study on the impact of falling rocks on the metal flexible net, and analyzed the effects of mesh size and diameter of high strength steel wire on bullet effect of the metal flexible net. Gentilini et al. [12] established a FE model of the metal flexible net by using two-node three-dimensional beam element type and analyzed the influence of mesh size and diameter of high strength steel wire on bullet effect of the metal flexible net. Generally speaking, the impact resistance of the metal flexible net mainly focuses on the analysis of the effect of mesh size and diameter of high-strength steel wire, while little research on the impact protection performance of the metal flexible net at different inclination angles has been carried out.

In this paper, experiments and FE analysis methods are used to study the oblique impact metal flexible net with different sizes and heights of falling rocks. The FE models of the oblique impact metal flexible net with falling rocks are 


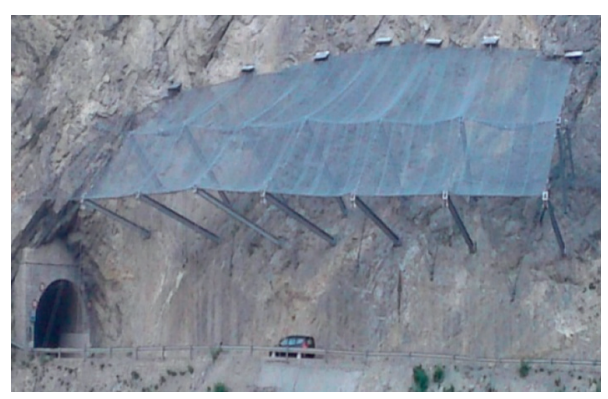

(a)

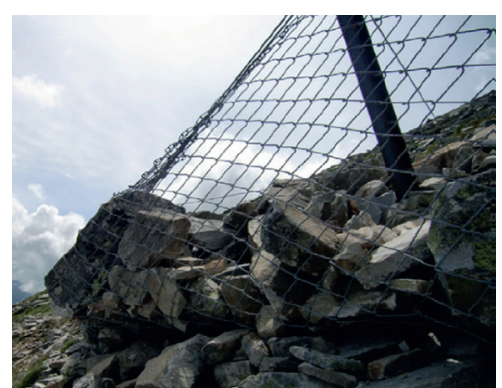

(b)

Figure 1: Application example of the metal flexible net in flexible protection system. (a) Cantilever flexible protection system. (b) Passive flexible protection system.

established and the validity was verified through comparing the results with that of test results. The impact resistance of the metal flexible net with different inclination angles to falling rocks is studied by FE methods.

\section{Model Experiments}

2.1. Experimental Design. The transverse one-to-one side of the T4/80 metal flexible net (a diameter of $4 \mathrm{~mm}$ for highstrength steel wire and an inner tangential circle diameter of $80 \mathrm{~mm}$ for a single net hole) with specification of $2.5 \mathrm{~m} \times 2.5 \mathrm{~m}$ produced by Chengdu Brooke Company is connected to the first and second supporting ropes with a diameter of $16 \mathrm{~mm}$. The two sides of the first supporting rope are fixed on the reaction frame of the front row and connected in series with \#1 and $\# 2$ push-pull force sensors; the two sides of the second supporting rope are fixed on the back row reaction frame, higher than the first supporting rope and connected in series with \#3 and \#4 push-pull force sensors. After installation, the angle between the horizontal plane and the plane of the metal flexible net is 30 degrees. The distance between the left and right reaction frames is $4.5 \mathrm{~m}$. Push-pull force sensor is connected with the dynamic test system through the bridge sensor, and highspeed camera is fixed in front of the metal flexible net. The experiment layout and connection modes are shown in Figures 2 and 3, respectively. The range of push-pull force sensors are $200 \mathrm{kN}$. The rated outputs of \#1, \#2, \#3, and \#4 are $1.4828 \mathrm{mv} / \mathrm{v}, 1.4882 \mathrm{mv} / \mathrm{v}, 1.4884 \mathrm{mv} / \mathrm{v}$, and $1.4946 \mathrm{mv} /$ $\mathrm{v}$, respectively. Prefabricated concrete blocks with 14-sided special-shaped cube with $1 / 3$ edge cut at the top corner which were used to simulate rock fall. The masses of concrete blocks were $20 \mathrm{~kg}$ and $50 \mathrm{~kg}$, respectively. The falling rocks were lifted by a crane in the laboratory hall. In order to achieve the free falling off and remote control of falling stones, an automatic decoupling device is installed between the crane hook and falling stones.

The experiments conditions of the oblique impact metal flexible net are listed in Table 1.

2.2. Experimental Process and Results. The falling rocks impacting the oblique (30 degrees) flexible net was conducted in a laboratory. The falling rocks, rebounding process, and deformation process of the metal flexible net were recorded by a high-speed camera (Sony, 239 frames per second). The instantaneous impact force on the supporting rope was recorded by the push-pull force sensors arranged at both sides of the supporting rope and the Tester Dynamic Test System. The process of falling rocks obliquely impacting the metal flexible net was recorded by a high-speed camera under XT-2.5-20-3 working condition, as shown in Figure 4.

In the experiment, the excitation voltage of the push-pull force sensors of $\# 1, \# 2, \# 3$, and $\# 4$ are all $10 \mathrm{~V}$, and the sensitivity is $0.07414 \mathrm{mV} / \mathrm{kN}, 0.07441 \mathrm{mV} / \mathrm{kN}, 0.07442 \mathrm{mV} /$ $\mathrm{kN}$, and $0.07473 \mathrm{mV} / \mathrm{kN}$, respectively. The sampling frequency of the dynamic testing system is $1 \mathrm{kHz}$. Define the initial tension force as zero relatively and set the values of sensors to zero. According to the dates of \#1, \#2, and \#3 and \#4 push-pull force sensors on the first support rope and the second support rope, the maximum instantaneous impact force under different conditions can be obtained which are shown in Table 2 .

\section{FE Analysis}

3.1. Establishment of FE Model. Considering the coupling effect of axial force and bending moment on the high strength steel wire and the existence of shear force at the joint, BEAM 161 element is used to simulate the metal flexible net, as shown in Figure 5. The default Hughes-Liu algorithm is selected for BEAM 161 beam element, and the integral criterion is $2 * 2$ Gauss integral. In order to find out the tensile properties of the metal flexible net, the tensile test of the four-grid metal flexible net was carried out. In the test, the mesh size of the metal flexible net is $83 \times 143 \mathrm{~mm}$. The diameter of high strength steel wire is $4 \mathrm{~mm}$ and the yield strength is $1770 \mathrm{MPa}$. The tensile test of four-grid metal flexible net is shown in Figure 6.

With respect to the supporting ropes, the axial force is the major factor while shear force and bending moment are negligible. Therefore, the supporting rope is simulated by LINK 160 element. With respect to the FE model of blocks, the SOLID 164 element was employed. Rock fall is simulated by 8-node three-dimensional solid explicit structural element SOLID 164. The plastic follow-up hardening model and Cowper-Symonds model are adopted, and the rigid body model is used to simulate rock fall. The mechanical properties of various materials in numerical 


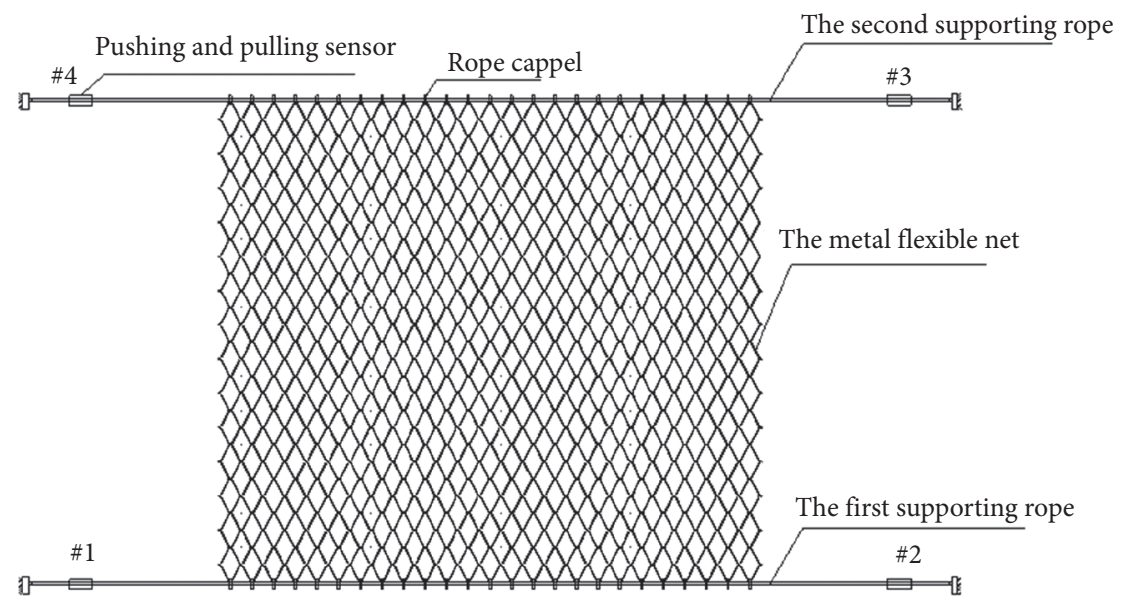

Figure 2: The arrangement scheme of experiment.

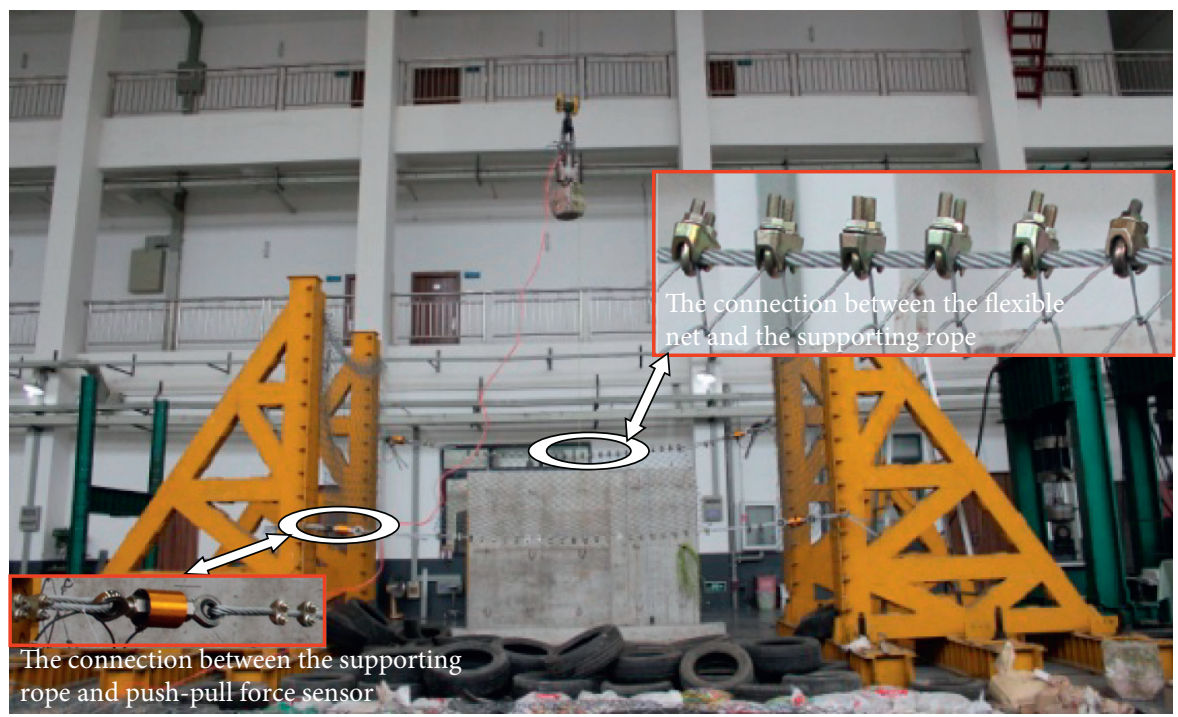

Figure 3: The slant antirock fall impact experiment.

TABLE 1: The conditions of slant antirock fall impact test.

\begin{tabular}{lccc}
\hline Rock fall quality $(\mathrm{kg})$ & Experiment conditions & Lifting height of falling stones $(\mathrm{m})$ & Impact location \\
\hline \multirow{2}{*}{20} & XT-2.5-20-2 & 2 & Metal flexible net center \\
& XT-2.5-20-3 & 3 & Metal flexible net center \\
50 & XT-2.5-50-2 & 2 & Metal flexible net center \\
& XT-2.5-50-3 & 3 & Metal flexible net center \\
\hline
\end{tabular}

calculation are shown in Table 3. The metal flexible net and supporting ropes exhibited high strain rates during the impact process, and this significantly impacts the hardening behaviour of elastic-plastic materials. Hence, a Cowper-Symonds model with strain rate dependency ( ${ }^{*}$ Mat Plastic Kinematic, 3\#) was used to account for the kinematic hardening property. In addition, the study showed that the failure of the metal flexible net is mainly caused by shear force. Therefore, the connection point between the high-strength steel wires in the metal flexible mesh is simplified as a coupling node, and the degree of freedom of translation is constrained while the degree of freedom of rotation is not constrained. In order to realize the boundary constraint of the supporting rope to the metal flexible net, the connection points between the metal flexible net and the supporting rope are coupled with degrees of freedom so that they have a common translational degree of freedom.

For calculating with ANSYS/LS-DYNA, the static and dynamic friction coefficients were all 0.8 [13], and the 


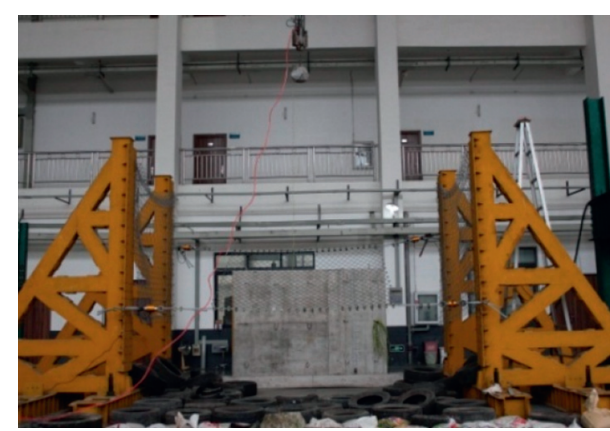

(a)

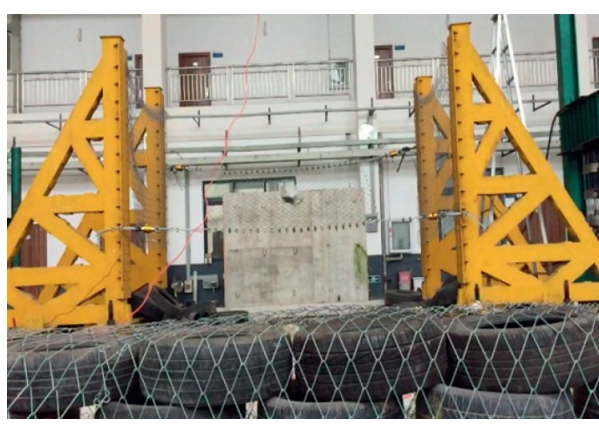

(c)

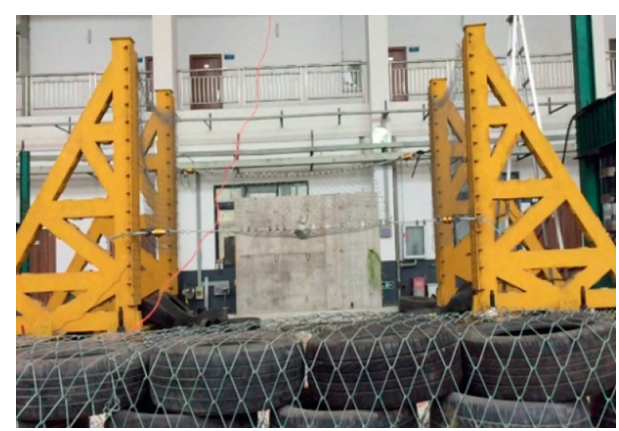

(b)

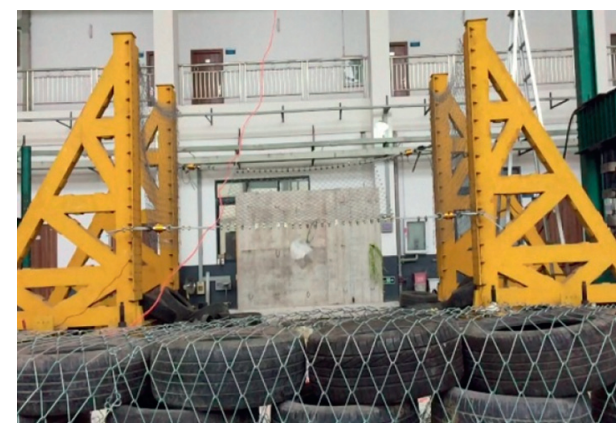

(d)

FIgURE 4: The rock fall slant impact under XT-2.5-20-3 condition. (a) The rock fall is hoisted. (b) The metal flexible net achieves maximum deformation. (c) Rock fall rebound. (d) The rock fall is ejected by the metal flexible net.

TABLE 2: The comparison table of the maximum instantaneous impact forces of the supporting ropes under different working conditions.

\begin{tabular}{lccccccc}
\hline \multirow{2}{*}{ Rock fall quality $(\mathrm{kg})$} & \multirow{2}{*}{ Test conditions } & \multicolumn{3}{c}{ First supporting rope $(\mathrm{kN})$} & \multicolumn{3}{c}{ Second supporting rope (kN) } \\
& & $1 \#$ & $2 \#$ & Average value & 3\# & 4\# & Average value \\
\hline \multirow{2}{*}{20} & XT-2.5-20-2 & 10.36 & 10.29 & 10.325 & 9.92 & 10.02 & 9.97 \\
& XT-2.5-20-3 & 13.34 & 12.96 & 13.15 & 12.79 & 12.83 \\
\multirow{2}{*}{50} & XT-2.5-50-2 & 24.22 & 24.04 & 24.13 & 22.33 & 22.55 \\
& XT-2.5-50-3 & 31.06 & 32.7 & 31.88 & 24.44 & 26.46 \\
\hline
\end{tabular}

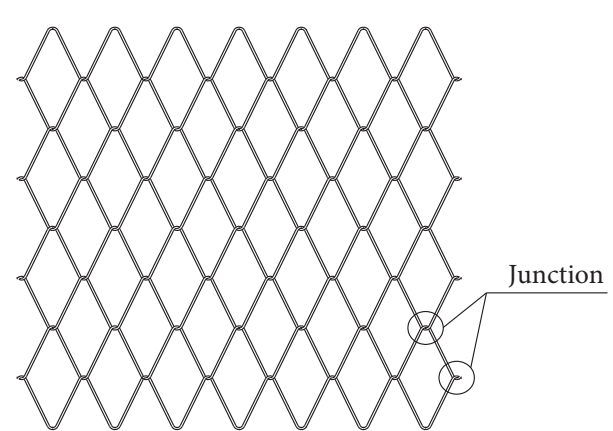

Figure 5: Schematic diagram of the metal flexible net.

contact between falling stones and metal flexible net was set as automatic one-sided contact. The initial contact time between the falling stone and the metal flexible net is set to zero. The initial contact velocity is calculated according to the height of the falling rock from the center of the metal flexible net. The total calculation time is $0.4 \mathrm{~s}$.
3.2. Verification of FE Model. In order to verify the validity of the FE model, the numerical simulation results and that of tests results are compared from the following three aspects: (1) deformation characteristics of the metal flexible net; (2) time history curves of impact force on the first and the second supporting rope; and (3) maximum instantaneous impact of supporting rope.

Figure 7 shows the results of numerical simulation and experiment of the metal flexible net impacted obliquely by a $50 \mathrm{~kg}$ falling stone at a height of $3 \mathrm{~m}$ (XT-2.5-50-3 working conditions). It can be seen that the numerical simulation is basically in agreement with the experiment. The FE numerical simulation method can simulate the dynamic process of the metal flexible net impacted by falling rocks. Figure 8 shows the comparison of the tension history curves of the first and second supporting ropes in the stage from the beginning of the falling stone contact metal flexible net to the end of the first impact under different working conditions by experiment (positive tension) and numerical calculation. The experimental results include the time history curves of $\# 1$, \#2, and, \#3 and \#4 push and pull force sensors, respectively. 


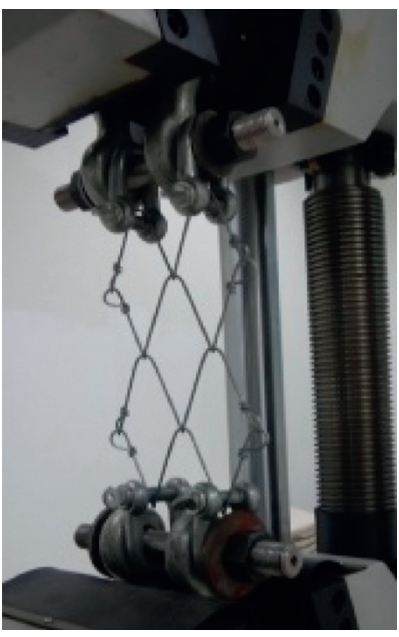

(a)

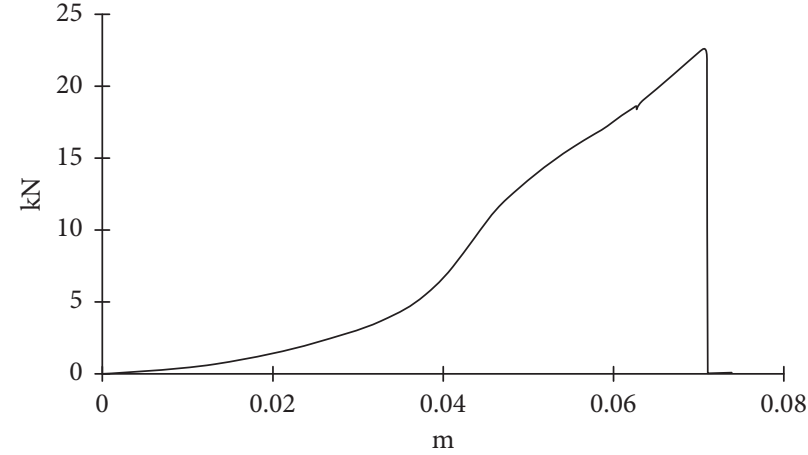

(b)

Figure 6: Tensile test of the four-mesh metal flexible net. (a) Tensile test. (b) Load-displacement curve.

TABLE 3: The mechanical parameters of various materials in numerical calculation.

\begin{tabular}{|c|c|c|c|c|c|c|c|}
\hline Material type & Elasticity modulus (GPa) & Yield strength $(\mathrm{MPa})$ & Density $\left(\mathrm{kg} / \mathrm{m}^{3}\right)$ & $C$ & $p$ & Poisson ratio & Limit strain \\
\hline High strength steel wire & 196 & 1770 & 7850 & 40 & 5 & 0.3 & 0.05 \\
\hline Supporting rope & 110 & 1770 & 7850 & 40 & 5 & 0.3 & 0.05 \\
\hline $20 \mathrm{~kg}$ rock fall & - & - & 2546 & - & - & 0.3 & - \\
\hline $50 \mathrm{~kg}$ rock fall & - & - & 2307 & - & - & 0.3 & - \\
\hline
\end{tabular}

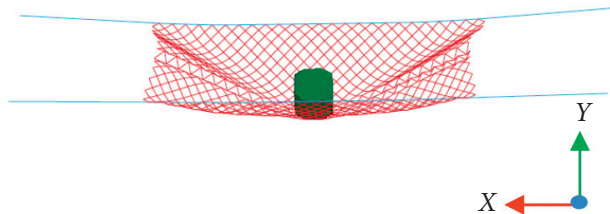

(a)

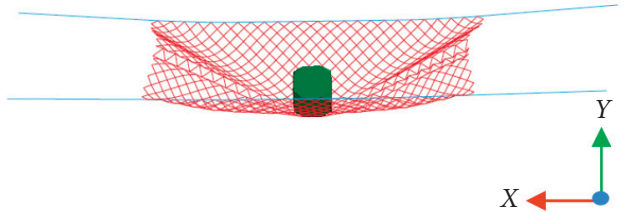

(c)

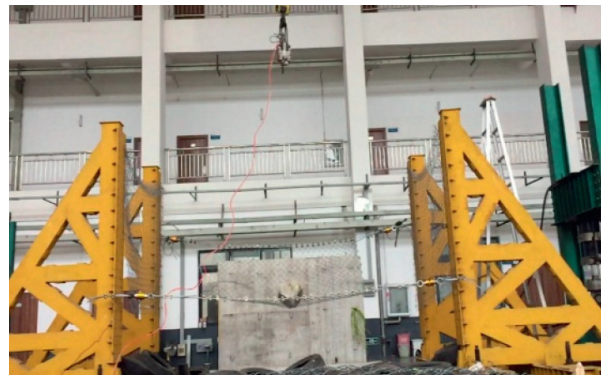

(b)

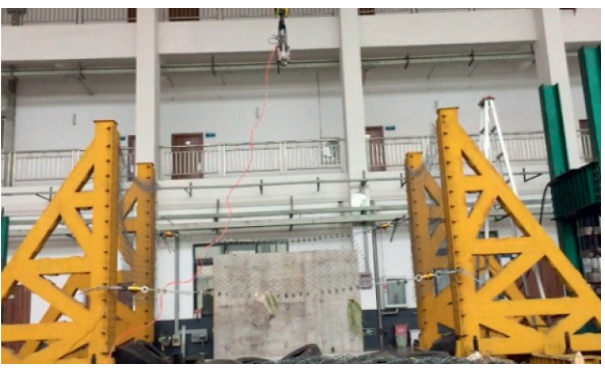

(d)

Figure 7: The comparison between numerical simulation and experiment of XT-2.5-50-3. (a) Maximum deformation of simulation. (b) Maximum deformation of experiment. (c) The falling rocks were ejected. (d) The falling rocks were ejected.

From Figure 8, it can be seen that the process from impact contact to peak impact load is basically consistent in the rising stage of the tension history curve of the supporting rope in the test and numerical analysis, which is also the main part of the design calculation. The maximum instantaneous impact force on the supporting rope during the impact of falling rocks on the metal flexible net under different working conditions are listed in Table 4. The 

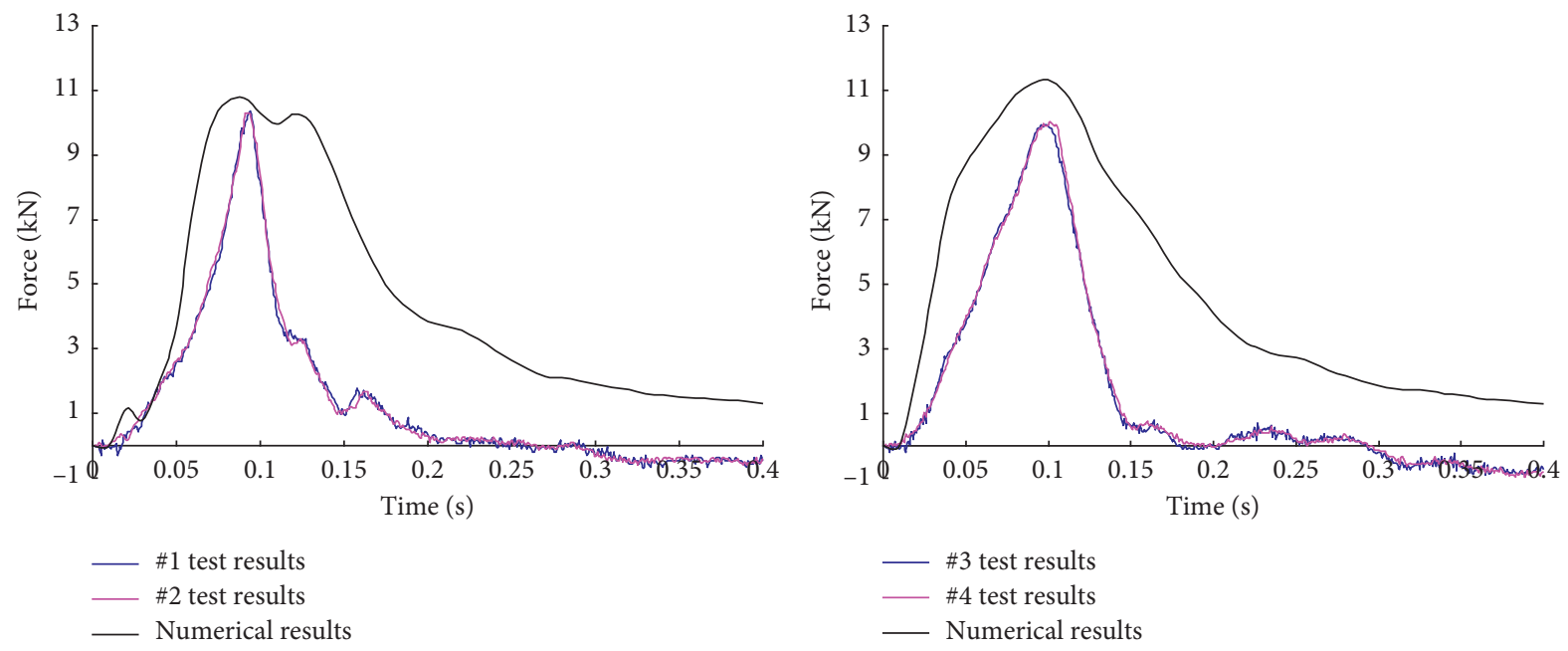

(a)
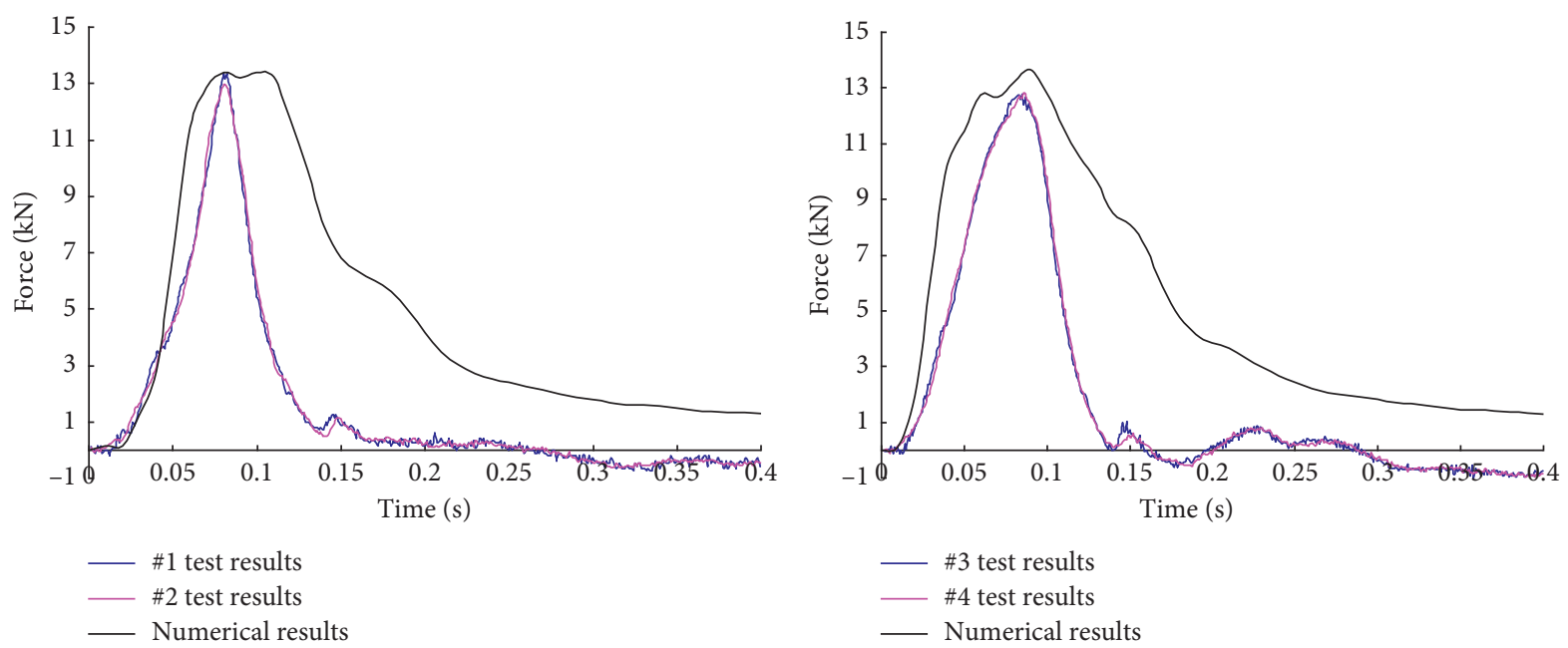

(b)
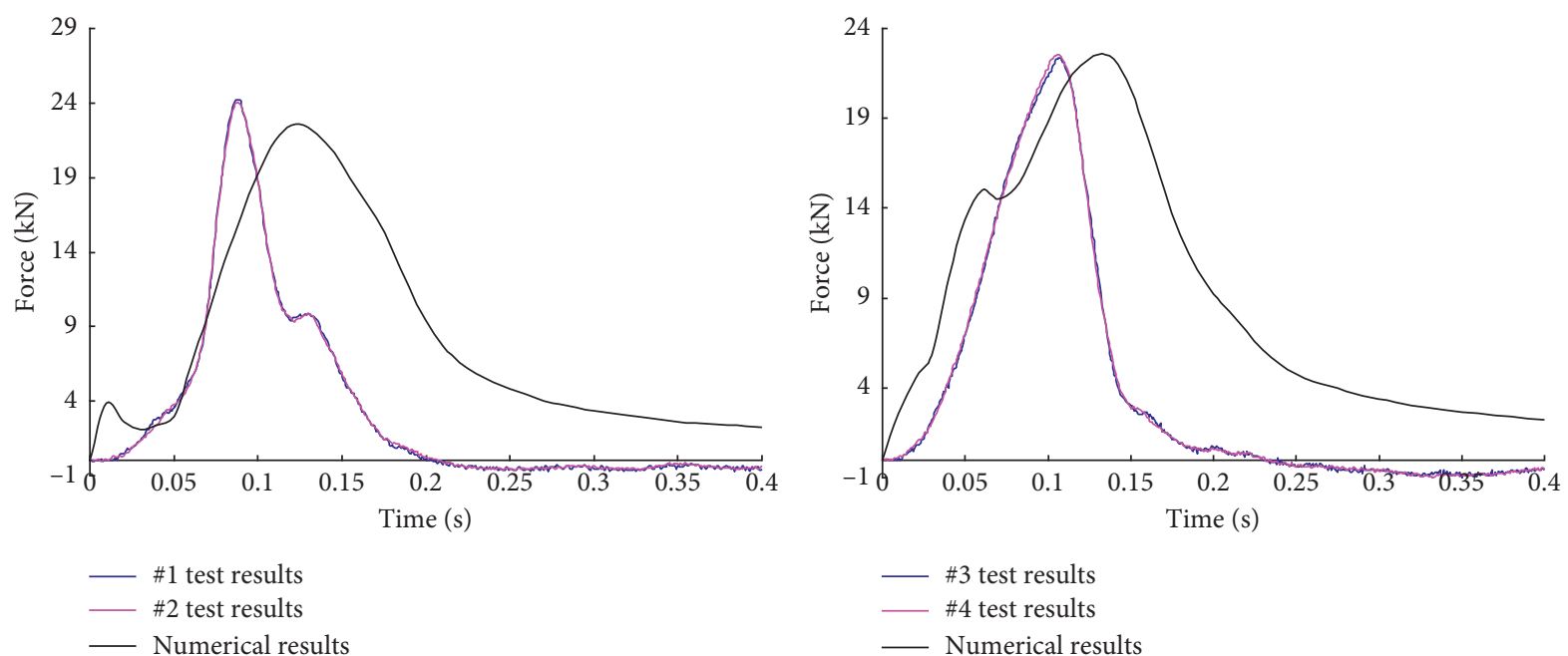

(c)

FIgURE 8: Continued. 

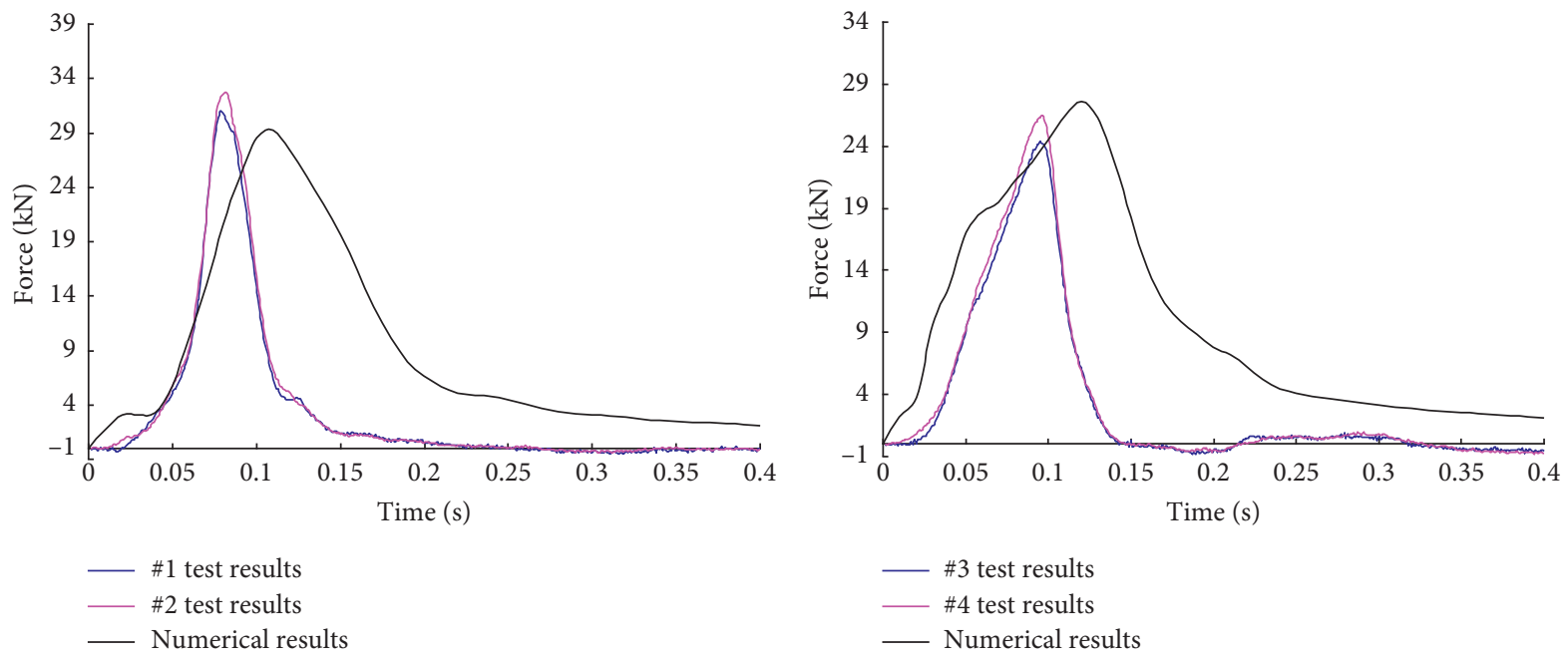

(d)

Figure 8: The contrast time history curves of the tension of the supporting rope. (a) Comparison between measurements under XT-2.5-20-2 conditions. (b) Comparison between measurement results under XT-2.5-20-3 working conditions. (c) Comparison between measurement results under XT-2.5-50-2 working conditions. (d) Comparison between measurement results under XT-2.5-50-3 working conditions.

TABLE 4: The comparison table of the maximum instantaneous impact forces of the supporting ropes under different working conditions.

\begin{tabular}{|c|c|c|c|c|c|c|c|}
\hline \multirow{2}{*}{ Rock fall quality (kg) } & \multirow{2}{*}{ Test conditions } & \multicolumn{3}{|c|}{ First supporting rope $(\mathrm{kN})$} & \multicolumn{3}{|c|}{ Second supporting rope $(\mathrm{kN})$} \\
\hline & & Numerical analysis & Testing & Error analysis & Numerical analysis & Testing & Error analysis \\
\hline \multirow{2}{*}{20} & XT-2.5-20-2 & 10.692 & 10.325 & 3.55 & 11.341 & 9.97 & 13.75 \\
\hline & XT-2.5-20-3 & 13.471 & 13.15 & 2.44 & 13.682 & 12.81 & 6.81 \\
\hline \multirow{2}{*}{50} & $\mathrm{XT}-2.5-50-2$ & 22.64 & 24.13 & 6.17 & 22.445 & 22.44 & 0.02 \\
\hline & XT-2.5-50-3 & 29.325 & 31.88 & 8.01 & 27.660 & 25.45 & 8.68 \\
\hline
\end{tabular}

experiment values of the first and second supporting ropes in the table are measured by \#1 and \#2 \#3 and \#4 push-pull force sensors, respectively, and the average value of the maximum instantaneous impact force is obtained (pull is positive) too. The comparison results show that the numerical simulation can accurately reflect the maximum impact force of the supporting rope during the impact process of falling rocks.

3.3. Analysis of Impact Resistance. Based on the effective numerical analysis model of oblique impact resistance of the metal flexible net, the impact resistance characteristics of the metal flexible net with different angles were analyzed.

Considering the geometric shape of the contact surface that does not vary with the angle of the metal flexible net when the rock falls in contact with the metal flexible net, the spherical model is used to replace the original polyhedron model. The density of the spherical model is $2500 \mathrm{~kg} / \mathrm{m}^{3}$ with $50 \mathrm{~kg}$ mass, and the impact velocity is $25 \mathrm{~m} / \mathrm{s}$. Figure 9 shows the acceleration timehistory curve of a flexible metal net impacted by falling rocks:

$$
a=\sqrt{a_{x}^{2}+a_{y}^{2}+a_{z}^{2}}
$$

where $a$ is the overall acceleration of falling rocks. $a_{x}, a_{y}$, and $a_{z}$ are the acceleration from $X$-axis, $Y$-axis, and $Z$-axis of falling rocks, respectively. Figure 10 shows the time-domain response of the impact force on the metal flexible net impacted by falling rocks. Figure 11 shows the time-domain response of the impact force on the first and second supporting ropes in the process of falling rocks impacting the metal flexible net.

Table 5 are the parameters of impact resistance of metal flexible nets with different angles extracted from numerical analysis. It can be seen that when the inclination angles of the metal flexible net are 15 degrees, 30 degrees, and 45 degrees, the rebound effect is better and the remaining height is increased, the protection width is increased obviously, and the impact force of the falling stone is reduced. Among them, the impact force of falling rocks at 45 degrees inclination decreases most obviously. In addition, the maximum instantaneous impact force of the supporting rope at 45 degrees of inclination is smaller than that of the supporting rope at 15 degrees and 30 degrees of inclination. In the case of the metal flexible net inclination angles of 60 degrees and 75 degrees, although the maximum instantaneous impact force of the falling stone and the maximum instantaneous impact force of the supporting rope are the smallest in the impact process, the protection width is smaller and the rebound effect after 


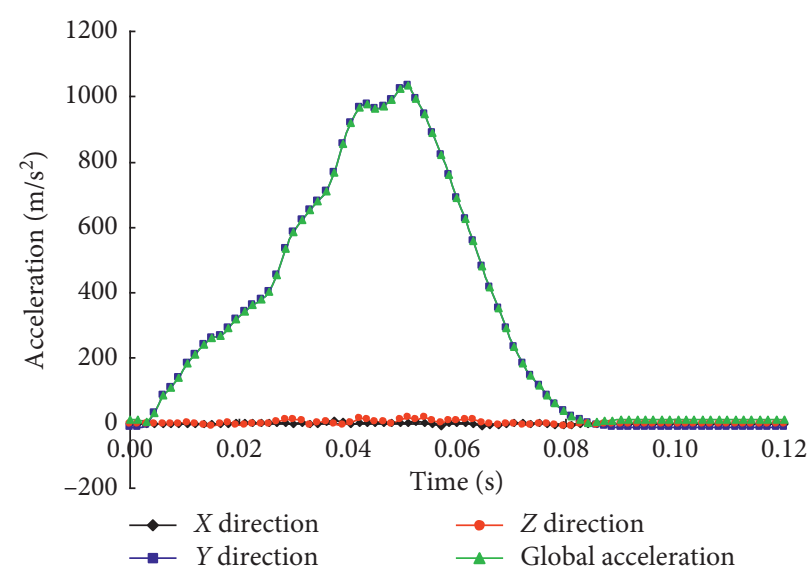

(a)

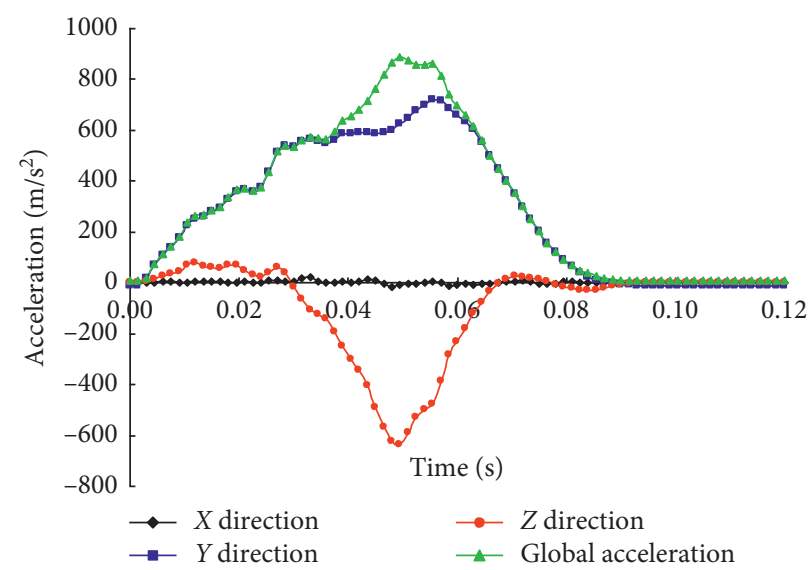

(c)

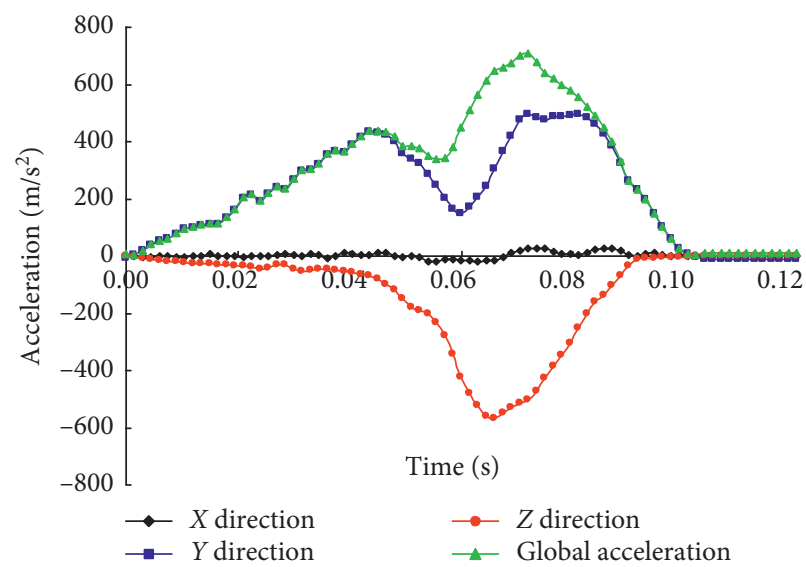

(e)

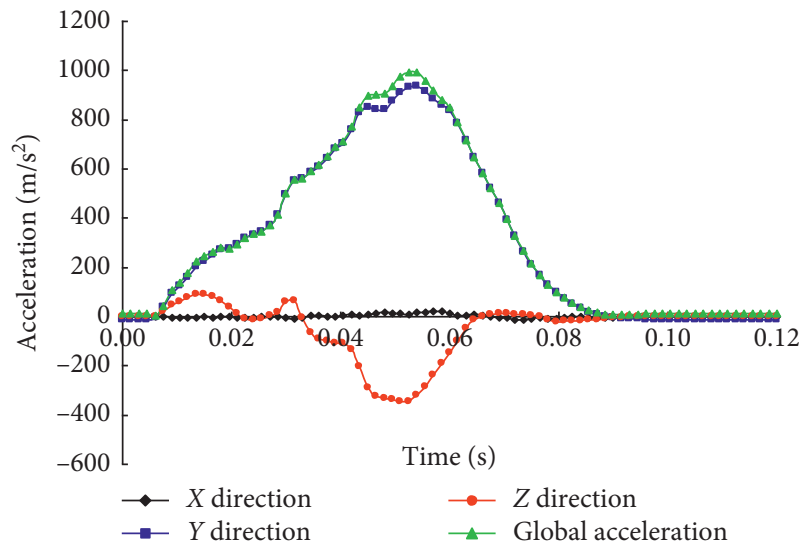

(b)

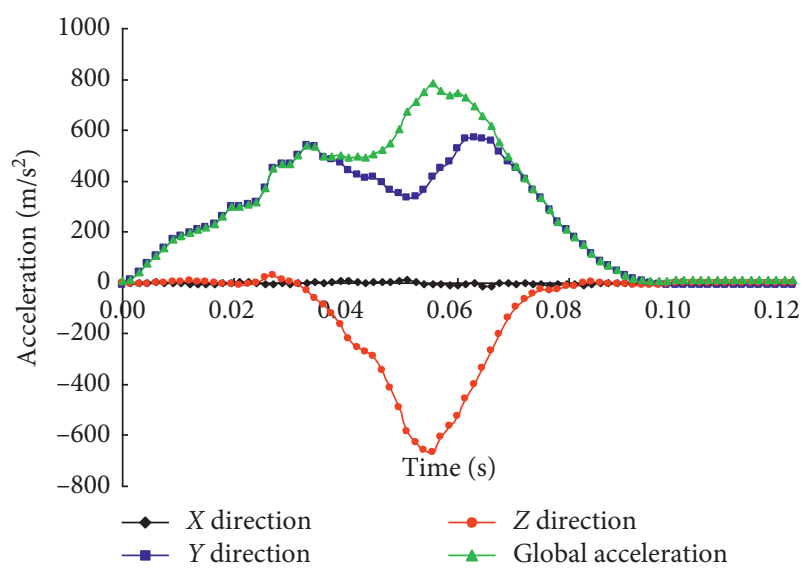

(d)

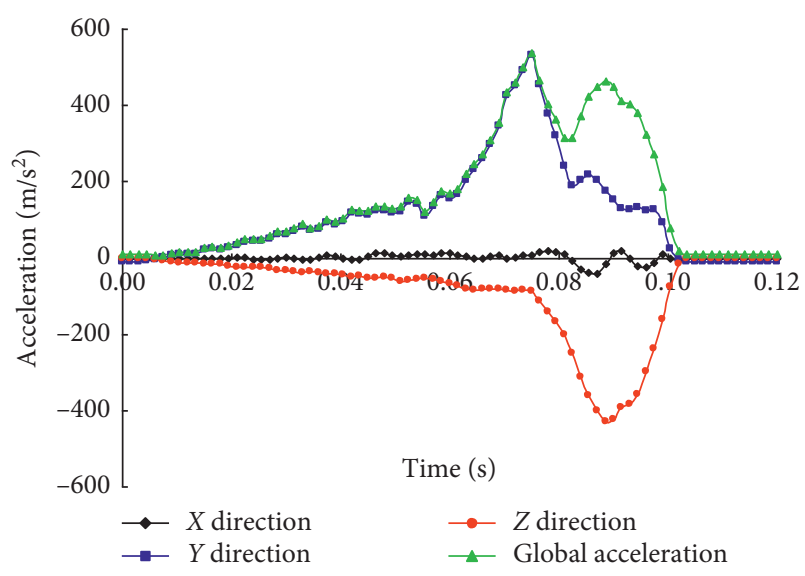

(f)

Figure 9: The acceleration time-domain curves of rock fall under different impact angles. (a) Acceleration time-history curve $\left(0^{\circ}\right)$. (b) Acceleration time-history curve $\left(15^{\circ}\right)$. (c) Acceleration time-history curve $\left(30^{\circ}\right)$. (d) Acceleration time-history curve $\left(45^{\circ}\right)$. (e) Acceleration time-history curve $\left(60^{\circ}\right)$. (f) Acceleration time-history curve $\left(75^{\circ}\right)$.

falling stone impact is not ideal. In the case of the metal flexible net inclination angle of 60 degrees, falling stone is entirely due to rolling impact. When the first supporting rope is hit and ejected, there is almost no rebound after impact when the inclination angle of the flexible metal net is 75 degrees. 


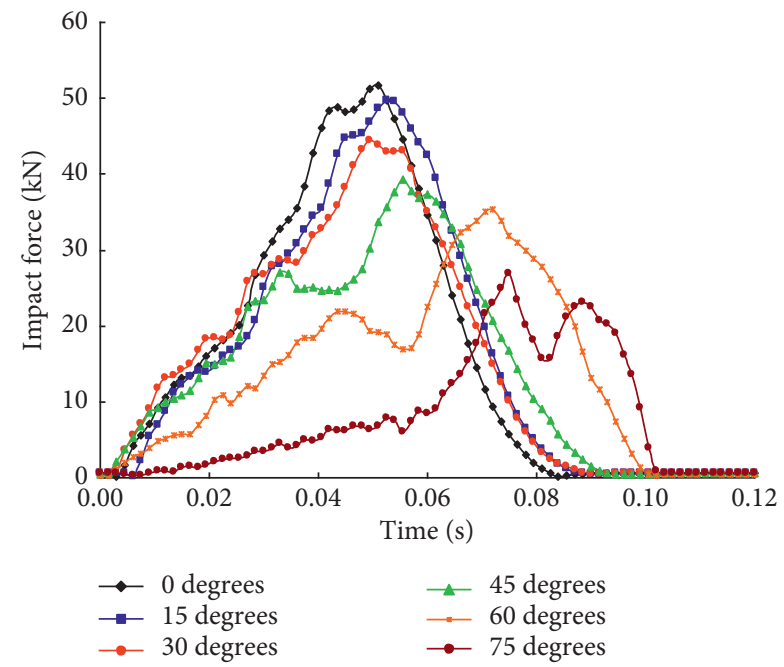

FIGURE 10: The time-domain responses of impact of rock fall under different impact angles.

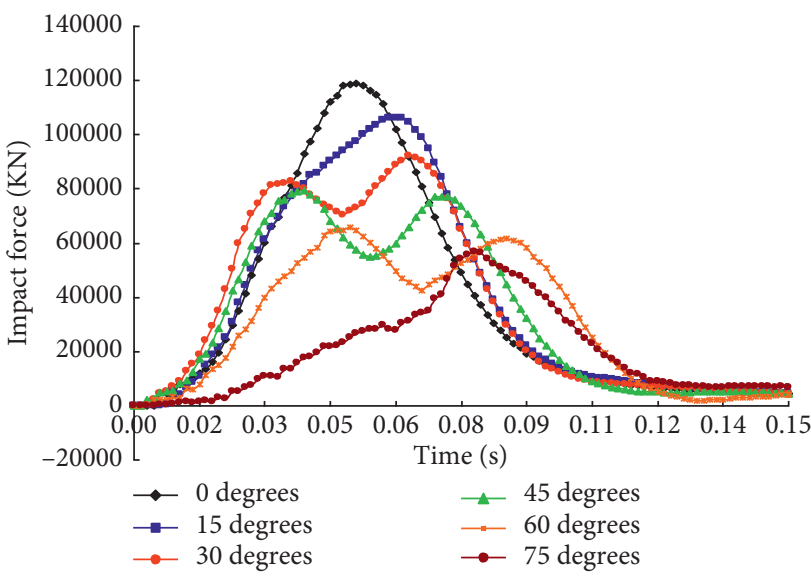

(a)

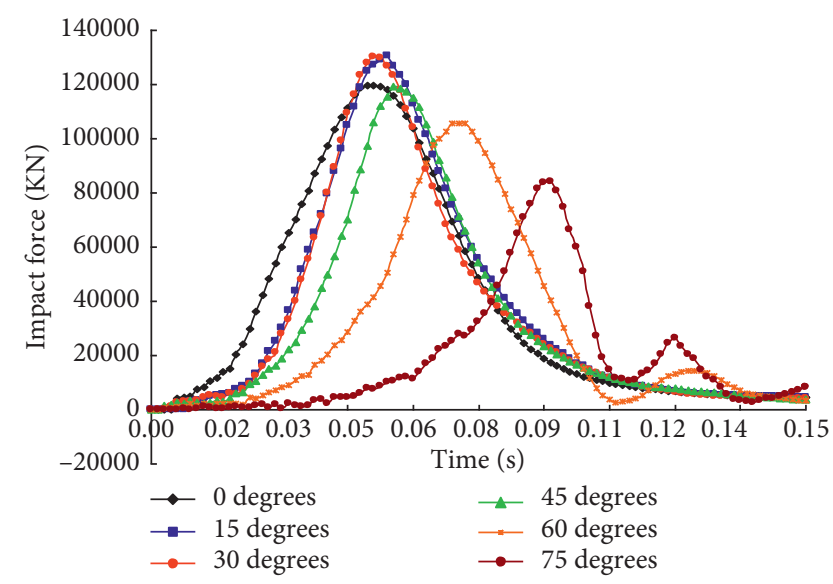

(b)

Figure 11: The time-domain responses of impact of supporting ropes with different impact angles. (a) First support rope. (b) Second supporting rope.

TABLE 5: The antirock fall impact performance under different impact angles.

\begin{tabular}{|c|c|c|c|c|c|c|}
\hline \multirow{2}{*}{$\begin{array}{l}\text { Inclination } \\
\text { angle }\left({ }^{\circ}\right)\end{array}$} & \multirow{2}{*}{$\begin{array}{l}\text { Remaining } \\
\text { height }(\mathrm{m})\end{array}$} & \multirow{2}{*}{$\begin{array}{l}\text { Protection } \\
\text { width }(\mathrm{m})\end{array}$} & \multirow{2}{*}{$\begin{array}{l}\text { Maximum instantaneous } \\
\text { impact force on rockfall } \\
\qquad(\mathrm{kN})\end{array}$} & \multicolumn{2}{|c|}{$\begin{array}{l}\text { Maximum instantaneous impact } \\
\text { force of support rope }(\mathrm{kN})\end{array}$} & \multirow{2}{*}{$\begin{array}{l}\text { The final stoning } \\
\text { position }\end{array}$} \\
\hline & & & & $\begin{array}{l}\text { First } \\
\text { supporting } \\
\text { rope }\end{array}$ & $\begin{array}{c}\text { Second } \\
\text { supporting rope }\end{array}$ & \\
\hline 0 & -0.87 & 2.5 & 51.69 & 119.75 & 119.75 & Metal flexible net \\
\hline 15 & -0.28 & 14.09 & 49.74 & 130.45 & 106.24 & Eject \\
\hline 30 & 0.025 & 19.47 & 44.50 & 130.13 & 92.00 & Eject \\
\hline 45 & 0.129 & 14.90 & 39.31 & 119.06 & 79.50 & Eject \\
\hline 60 & 0 & 7.49 & 35.35 & 105.75 & 65.69 & $\begin{array}{c}\text { Roll to the first } \\
\text { supporting rope and } \\
\text { eject }\end{array}$ \\
\hline 75 & 0 & 0.64 & 26.88 & 84.15 & 56.71 & $\begin{array}{l}\text { Roll out, almost no } \\
\text { bullet appears }\end{array}$ \\
\hline
\end{tabular}




\section{Conclusion}

Based on experiments and numerical analysis, the impact resistance of the metal flexible net against falling rocks was studied. The experiments of oblique (30 degrees) impact resistance of the metal flexible net were carried out. The corresponding FE model to the experiments was established. Comparisons between FE model and experiments results were made from three aspects: deformation characteristics of the metal flexible net, time-history curve of impact force borne by the supporting rope, and maximum instantaneous impact force borne by the supporting rope. The validity of the FE model is verified. An effective FE analysis platform is established for the study of the impact resistance of metal flexible nets to falling rocks. At the same time, numerical models of metal flexible nets with inclination angles of 0,15 , $30,45,60$, and 75 degrees are established, and the impact resistance of metal flexible nets with different inclination angles is analyzed. The main conclusions are as follows:

(1) The metal flexible net with proper inclination can bounce the impact rock fall out of the safe area, avoid the rock fall remaining on the metal flexible net, and achieve the self-cleaning function.

(2) When the inclination angle of the metal flexible net are 15, 30, and 45 degrees, the bouncing effect is better, the remaining height is increased, the protection width is increased obviously, and the impact force of the falling stone is reduced, especially when the inclination angle is 45 degrees. In addition, the maximum instantaneous impact force of the supporting rope at 45 degrees of inclination is smaller than that of the supporting rope at 15 degrees and 30 degrees of inclination.

(3) When the inclination angle of the metal flexible net is 60 degrees and 75 degrees, the maximum instantaneous impact force of falling stone and the maximum instantaneous impact force of the supporting rope are the smallest in the impact process, but the protection width is smaller, and the rebound effect after rock fall impact is not ideal. In the case of 60 degree inclination angle of the metal flexible net, the falling rocks were ejected entirely from the falling impact on the first supporting rope. Under the condition of 75 degree inclination of the metal flexible net, there was almost no ejection phenomenon after impact.

(4) The rock fall protection performance of the metal flexible net with an inclination of 45 degrees is relatively good, which provides a reference for the engineering application of the metal flexible net.

(5) In the paper, the test rock fall included 14-face precast polyhedron concrete blocks in which the shapes are in agreement with SAEFL guidelines. In nature, the shapes of rock falls are different. For the flexible protection system, the more the edges and corners of rock fall, the more obvious the damping and cushioning of the metal flexible net.
(6) The experiments results show that the structure can resist the impact of falling rocks effectively and can be profitably used along roads or rock slopes widely.

\section{Data Availability}

The data used to support the findings of this study are available from the corresponding author upon request.

\section{Conflicts of Interest}

The authors declare that there are no conflicts of interest regarding the publication of this paper.

\section{Acknowledgments}

This research was supported by the China Postdoctoral Science Foundation (Grant no. 2019M664020).

\section{References}

[1] P. Bertolo, C. Oggeri, and D. Peila, "Full-scale testing of draped nets for rock fall protection," Canadian Geotechnical Journal, vol. 46, no. 3, pp. 306-317, 2009.

[2] A. Volkwein, A. Roth, W. Gerber, and A. Vogel, "Flexible rock fall barriers subjected to extreme loads," Structural Engineering International, vol. 19, no. 3, pp. 327-332, 2009.

[3] P. Asteriou and G. Tsiambaos, "Empirical model for predicting rock fall trajectory direction," Rock Mechanics and Rock Engineering, vol. 49, no. 3, pp. 927-741, 2016.

[4] A. Mentani, A. Giacomini, O. Buzzi, L. Govoni, G. Gottardi, and S. Fityus, "Numerical modelling of a low-energy rock fall barrier: new insight into the bullet effect," Rock Mechanics and Rock Engineering, vol. 49, no. 4, pp. 1247-1262, 2016.

[5] E. Blanco-Fernandez, D. Castro-Fresno, J. J. Del Coz Diaz, and J. Díaz, "Field measurements of anchored flexible systems for slope stabilization: evidence of passive behavior," Engineering Geology, vol. 153, pp. 95-104, 2013.

[6] L. Ma, J. Wu, M. Wang, D. Lu, and H. Wei, "Dynamic compressive properties of dry and saturated coral rocks at high strain rates," Engineering Geology, vol. 272, Article ID 105615, 2020.

[7] Y. Yang, Y. Zhenhua, Y. Tao, and et.al., Flexible Protection System and its Engineering Design and Application, Science Press, Beijing, China, 2015.

[8] S. Q. Shi, M. Wang, X. Q. Peng, and Y. K. Yang, "A new-type flexible rock-shed under the impact of rock block: initial experimental insights," Natural Hazards and Earth System Sciences, vol. 13, no. 12, pp. 3329-3338, 2013.

[9] J. J. Del Coz Díaz, P. J. García Nieto, D. Castro Fresno, and E. Blanco Fernández, "Non-linear analysis of cable networks by FEM and experimental validation," International Journal of Computer Mathematics, vol. 86, no. 2, pp. 301-313, 2009.

[10] F. Nicot, B. Cambou, and G. Mazzoleni, "Design of rock fall restraining nets from a discrete element modelling," Rock Mechanics and Rock Engineering, vol. 34, no. 2, pp. 99-118, 2001.

[11] J. P. Escallón, C. Wendeler, E. Chatzi, and P. Bartelt, "Parameter identification of rock fall protection barrier components through an inverse formulation," Engineering Structures, vol. 77, pp. 1-16, 2014.

[12] C. Gentilini, L. Govoni, S. De Miranda, G. Gottardi, and F. Ubertini, "Three-dimensional numerical modelling of 
falling rock protection barriers," Computers and Geotechnics, vol. 44, pp. 58-72, 2012.

[13] G. Murray, F. Gandhi, and C. Bakis, "Flexible matrix composite skins for one-dimensional wing morphing," Journal of Intelligent Material Systems and Structures, vol. 21, no. 17, pp. 1771-1781, 2010. 